\title{
Avaliação de fermentados botânicos no controle de Colletotrichum fructicola isolado
}

\section{de Acca sellowiana}

\author{
Evaluation of botanical fermentates in the control of Colletotrichum fructicola isolated from Acca \\ sellowiana \\ Evaluación de fermentatos botánicos en el control de Colletotrichum fructicola aislado de Acca \\ sellowiana
}

Recebido: 16/04/2021 | Revisado: 25/04/2021 | Aceito: 30/04/2021 | Publicado: 15/05/2021

\author{
Bruno Costa \\ ORCID: https://orcid.org/0000-0002-1050-3213 \\ Universidade de Caxias do Sul, Brasil \\ E-mail: bcosta@ucs.br \\ Marcia Regina Pansera \\ ORCID: https://orcid.org/0000-0002-6868-829X \\ Universidade de Caxias do Sul, Brasil \\ E-mail: mrpancer@ucs.br \\ Valdirene Camatti Sartori \\ ORCID: https://orcid.org/0000-0002-8107-5893 \\ Universidade de Caxias do Sul, Brasil \\ E-mail: vcsartor@ucs.br
}

\begin{abstract}
Resumo
Acca sellowiana (O. Berg) Burret (feijoa) é uma frutífera nativa do sul do Brasil, com elevado potencial para cultivo, principalmente para agricultores familiares, tendo perspectivas positivas quanto à adaptação se comparada às demais frutíferas comerciais. A principal doença da cultura é a antracnose causada pelo fungo Colletotrichum spp., que não possui produtos fitossanitários registrados para seu controle. O objetivo desse trabalho foi verificar a atividade antifúngica in vitro de diferentes fermentados botânicos sobre o desenvolvimento do fitopatógeno Colletotrichum fructicola. Foi avaliada inibição do crescimento micelial in vitro com a medição do diâmetro perpendicular para determinar a porcentagem de inibição de crescimento fúngico em triplicata. Os tratamentos foram constituídos dos fermentados botânicos de Schinus terebinthifolia, Psisum sativum, Tagetes minuta, Trifolium pratense, Ilex paraguarienses, Vernonanthura tweediana, Prunus myrtifolia e Amaranthus hybridus avaliados nas concentrações de 10, 20 e $40 \%$ e testemunha. O principal composto fenólico identificado via HPLC foi ácido gálico a partir do fermentado de $S$. terebinthifolia. Foi possível verificar que o fermentado de $S$. terebinthifolia na concentração de $40 \%$ inibiu totalmente o desenvolvimento de Colletotrichum fructicola. Os demais fermentados avaliados neste trabalho não demonstraram efeito satisfatório sobre este fungo fitopatogênico.
\end{abstract}

Palavras chave: Plantas do futuro; Controle alternativo da antracnose; Fermentados botânicos.

\begin{abstract}
Acca sellowiana (O. Berg) Burret (feijoa) a fruit native to southern Brazil, with high potential for cultivation, especially for family farmers, with positive prospects for adaptation compared to other commercial fruit. The main disease of the crop is anthracnose caused by the fungus Colletotrichum spp., Which does not have phytosanitary products registered for its control. The objective of this work was to verify the antifungal activity in vitro of different botanical fermentates on the development of the phytopathogen Colletotrichum fructicola. Inhibition of mycelial growth was evaluated in vitro by measuring the perpendicular diameter to determine the percentage of inhibition of fungal growth in triplicate. The treatments consisted of botanical fermented Schinus terebinthifolia, Psisum sativum, Tagetes minuta, Trifolium pratense, Ilex paraguarienses, Vernonanthura tweediana, Prunus myrtifolia and Amaranthus hybridus, to be evaluated in concentrations of 10,20 and $40 \%$ and witness. The main phenolic compound identified via HPLC was gallic acid from the fermented S. terebinthifolia. It was possible to verify that the fermentation of S. terebinthifolia at a concentration of $40 \%$ totally inhibited the development of Colletotrichum fructicola. The other fermentates evaluated in this work did not demonstrate a satisfactory effect on this phytopathogenic fungus.
\end{abstract}

Keywords: Plants of the future; Alternative control of anthracnose; Botanical fermentations. 


\begin{abstract}
Resumen
Acca sellowiana (O. Berg) Burret (feijoa) una fruta originaria del sur de Brasil, con alto potencial de cultivo, especialmente para los agricultores familiares, con perspectivas positivas de adaptación frente a otras frutas comerciales. La principal enfermedad del cultivo es la antracnosis causada por el hongo Colletotrichum spp., El cual no cuenta con productos fitosanitarios registrados para su control. El objetivo de este trabajo fue verificar la actividad antifúngica in vitro de diferentes fermentados botánicos sobre el desarrollo del fitopatógeno Colletotrichum fructicola. La inhibición del crecimiento micelial in vitro se evaluó midiendo el diámetro perpendicular para determinar el porcentaje de inhibición del crecimiento fúngico por triplicado. Los tratamientos consistieron en fermentados botánicos Schinus terebinthifolia, Psisum sativum, Tagetes minuta, Trifolium pratense, Ilex paraguarienses, Vernonanthura tweediana, Prunus myrtifolia y Amaranthus hybridus, para ser evaluados en concentraciones de 10, 20 y $40 \%$ y testigo. El principal compuesto fenólico identificado mediante HPLC fue el ácido gálico de la $S$. terebinthifolia fermentada. Se pudo comprobar que la fermentación de S. terebinthifolia a una concentración del $40 \%$ inhibió totalmente el desarrollo de Colletotrichum fructicola. Los otros fermentados evaluados en este trabajo no demostraron un efecto satisfactorio sobre este hongo fitopatógeno.
\end{abstract}

Palabras clave: Plantas del futuro; Control alternativo de la antracnosis; Fermentaciones botánica.

\title{
1. Introdução
}

O gênero Colletotrichum é um dos mais importantes gêneros de fungos fitopatógenos (Dean et al., 2012), atuando sobre perdas na produtividade agrícola, principalmente nas regiões tropicais e subtropicais do mundo Silva et al., (2006). Em razão da sua ampla distribuição mundial, alta capacidade de infecção e importância científica como modelo de patossistema, o gênero encontra-se entre os dez principais fungos causadores de doenças em plantas (Dean et al., 2012). Várias espécies de Colletotrichum são agentes causadores da antracnose em uma ampla variedade de culturas, incluindo cereais (Parreira et al., 2014), hortaliças (Reis et al., 2009) e várias espécies de frutas (Peng et al., 2013; Ribeiro et al., 2016; Gan et al., 2016).

Na cultura de Acca sellowiana, a principal doença é a antracnose causada pelo fungo Colletotrichum spp. podendo causar seca parcial dos ramos evoluindo para a morte das plantas tanto jovens quanto adultas, perdas de até $100 \%$ dos frutos e morte das plântulas nas sementeiras por sementes originadas de frutos infectados, sendo os tecidos jovens das plantas os mais suscetíveis Andrade e Ducroquet (1994). Para Lopes (2013) a doença está associada principalmente ao C. gloeosporioides e C. acutatum duas espécies do gênero Colletotrichum.

$\mathrm{O}$ uso de agrotóxicos tem sido amplamente utilizados no controle da antracnose (Johnny et al., 2011). Devido à toxicidade, esses produtos podem contaminar o ambiente (Candido Silva et al., 2013), e elevar os custos de produção (Perina, 2014). Os efeitos negativos do uso indiscriminado de agrotóxicos tem incentivado a busca por métodos alternativos no manejo de doenças de culturas agrícolas e alguns estudos tem apresentado resultados promissores no controle de diversos fungos fitopatogênicos (Camatti-Sartori et al., 2011; Naruzawa et al., 2011; Venturoso et al., 2011a; Venturoso et al., 2011b).

Na produção agroecológica já vem sendo empregadas diferentes práticas e tratamento fitossanitários alternativos, com baixa ou nenhuma agressividade ao homem e a natureza, além de facilidade de aquisição, emprego, manejo e aplicação, consideradas como tecnologias sociais ao alcance principalmente do pequeno agricultor (Sartori \& Venturin, 2016). Como alternativa promissora no controle de fitopatógenos, os extratos vegetais são constituídos de vários compostos metabólitos, incluindo alcalóides, flavonóides, isoflavonóides, taninos, cumarinas, glicosídeos, terpenos, fenilpropanonas e ácidos orgânicos. Isso lhes confere vantagens como ter diferentes modos de ação, o que dificulta o desenvolvimento da resistência pelo patógeno, além de amplo espectro de ação (Cabral et al., 2013).

Preparados de plantas bioativas vêm sendo utilizados visando redução do uso de fungicidas químicos (Domingues et al., 2020). Estes preparados vegetais apresentam resultados promissores no controle de vários fitopatógenos, através de indução de mecanismos de resistência, o que favorece a proteção de plantas cultivadas (Cruz et al., 2011). E o modo pelo qual os macerados de plantas bioativas atuam pode ser atribuído tanto a ação fungitóxica, quanto à indução o de resistência (Toledo et al., 2015; Melo et al., 2016). 
Efeitos favoráveis no controle de fungos e de insetos praga a partir de fermentados botânicos até então são escassos, o que justifica a relevância da pesquisa sobre o potencial de determinadas plantas sobre o controle de fungos fitopatogênicos. Bertrand et al. (2008) apresentam informações sobre dados experimentais quanto ao preparo e uso de fermentados de plantas sobre a sanidade de plantas cultivadas.

Segundo Sartori e Venturin (2016), produtores voltados à agricultura orgânica usam como métodos de controle alternativo de doenças, extratos vegetais oriundos de folhas, frutos e sementes coletadas localmente, além de já ser evidenciada a menor perda de produção com o uso de fermentados botânicos. Nos fermentados botânicos o processo de fermentação ocorre de maneira espontânea e aeróbica em ambiente escuro. Segundo Pietrobelli (2019) o processo de fermentação tem como objetivo extrair a clorofila e a seiva celular das plantas para potencializar o efeito das substâncias extraídas além da propagação de microrganismos benéficos, tornando tal um produto vivo possuidor de ação terapêutica e fisiológica.

A utilização de diferentes métodos alternativos visando o controle de Colletotrichum gloeosporioides proporciona uma redução da utilização de produtos químicos e tem sido investigado por Araújo et al (2018), Nobre e Marques (2021).

Este trabalho avaliou a atividade antifúngica in vitro, de diferentes fermentados botânicos sobre o desenvolvimento de Colletotrichum fructicola isolado de Acca sellowiana.

\section{Metodologia}

O experimento foi desenvolvido no Laboratório de Agricultura Orgânica da Universidade de Caxias do Sul (UCS) Caxias do Sul, no período de julho a novembro de 2019. O fungo Colletotrichum spp. foi isolado de frutos de Acca sellowiana com sintoma de doença, purificado e armazenado em meio de cultura BDA, sendo que este foi enviado para identificação no Laboratório de Diagnóstico Molecular - Universidade de Caxias do Sul. Os fungos foram crescidos em meio caldo batata dextrose por 48 horas a $28^{\circ} \mathrm{C}, 1,0 \mathrm{~mL}$ foi centrifugado $(10.000 \mathrm{xg}$ por $3 \mathrm{~min})$ e o pellet foi utilizado para a extração do DNA seguindo a metodologia de Tapia-Tussel et al (2006).

Os primers NL1 (5'-GCATATCAATAAGCGGAGGAAAAG-3') e NL-4 (5'-GGTCCGTGTTTCAAGACGG-3') foram utilizados para amplificar um fragmento da região 5' terminal do 28S rRNA abrangendo as regiões D1 e D2 (Maoura et al., 2005). As reações de amplificação continham: $50 \mathrm{ng}$ de DNA; $2,0 \mathrm{mM}$ de $\mathrm{MgCl}_{2} ; 0,2 \mathrm{mM}$ de dNTP; $0,2 \mathrm{pmol} / \mu \mathrm{l}$ de cada um dos primers e 0,05 U/ $\mu 1$ de Taq DNA Polimerase (Invitrogen do Brasil). A reação foi amplificada em termociclador com temperatura para abertura das fitas de DNA de $94^{\circ} \mathrm{C}$ por $30 \mathrm{seg}$, temperatura para ligação dos primers de $58^{\circ} \mathrm{C}$ por 30 seg e elongação de $72^{\circ} \mathrm{C}$ por $45 \mathrm{seg}$, foram programados 35 ciclos de amplificação. A presença e quantificação dos fragmentos de DNA amplificados foram verificadas por eletroforese em gel de agarose $2,5 \%$ e avaliada em luz UV, como marcador de peso molecular foi utilizado LowMass (Invitrogen).

Os produtos de PCR foram tratados com as enzimas exonuclease I e shrimp alcaline phosphatase (USB) antes do sequenciamento. A reação de sequenciamento foi realizada com o kit BigDye Terminator v3.1 Sequencing Kit (Thermo Fisher Scientific) seguindo as recomendações do fabricante e adicionando $0,25 \mu \mathrm{M}$ de primer e aproximadamente $100 \mathrm{ng}$ de produto de PCR purificado. As amostras foram amplificadas em termociclador e após foram purificadas com o BigDye XTerminator Purification Kit (Thermo Fisher Scientific) e inseridas no sequenciador 3500 Genetic Analyzer (Thermo Fisher Scientific). Os dados foram coletados pelo programa Data Collection (Thermo Fisher Scientific). Para a identificação do isolado as sequências geradas foram comparadas com sequências depositadas no GenBank. O fungo foi identificado como Colletotrichum fructicola - ITS MT 988391.

As plantas avaliadas foram coletadas na área da Universidade de Caxias do Sul $(-29.163003,-51145408)$ e na propriedade do Bairro de Galópolis, Caxias do Sul-RS, na Capela São Francisco da 6a légua (-29.219396, -51.134663). Após a coleta as mesmas foram enviadas para identificação junto ao Museu de Ciências Naturais. As plantas utilizadas foram aroeira 
vermelha (Schinus terebinthifolia Raddi) HUCS 49955, ervilha (Psisum sativum L.) HUCS 50016, cravo-de-defunto (Tagetes minuta L.) HUCS 49951, trevo vermelho (Trifolium pratense L.) HUCS 49952, erva mate (Ilex paraguarienses A. ST.-Hil.) HUCS 25274, assa-peixe (Vernonanthura tweediana (Baker) H. Rob.) HUCS 50017, pessegueiro bravo (Prunus myrtifolia (L.) Urb.) HUCS 49949, e caruru (Amaranthus hybridus L.) HUCS 49954.

Os fermentados foram preparados utilizando 500 gramas de planta fresca triturada (folhas, frutos ou planta inteira) adicionados a 1,5 L de água de fonte (não tratada), colocados em recipiente de 5,0 L protegido por tecido do tipo voal e mantidos no escuro durante 15 dias a uma temperatura média de $25^{\circ} \mathrm{C}$ para que ocorra fermentação aeróbica Triaca et al (2018). Após foi realizada a prensagem para extração da parte líquida do fermentado e medição do pH com o auxílio de phmetro digital, e corrigidos para valores próximo a 6,0 necessária para posterior solidificação do meio de cultura, com a utilização de solução de $\mathrm{NaOH}$ de $2 \mathrm{~mol} / \mathrm{L}$.

Para verificar a atividade antifúngica dos fermentados botânicos, foram preparados meios de cultura BDA (BatataDextrose-Ágar), e, ainda fundente foram adicionados os fermentados botânicos nas concentrações de $0,10,20$ e $40 \%$, cuja $0 \%$ corresponde ao controle e após autoclavados a $121^{\circ} \mathrm{C}$ por $15 \mathrm{~min}$. Os mesmos foram vertidos em placas de Petri, em cinco repetições, e após a solidificação do meio foi depositado no centro da placa um disco micelial de $5 \mathrm{~mm}$ do fungo C. fructicola com sete dias de crescimento. As placas foram vedadas e mantidas incubadas em câmeras tipo BOD, a temperatura de $25 \pm 2{ }^{\circ} \mathrm{C}$, umidade relativa entre 60 e $80 \%$, com foto período de 12 horas, segundo Triaca et al (2018).

Foram medidos os diâmetros de crescimento micelial ao $3^{\circ}, 7^{\circ}$ e $14^{\circ}$ dia após a inoculação, e com os dados obtidos foi determinada a porcentagem de inibição de crescimento (PIC) dos tratamentos em relação à testemunha, conforme a fórmula de Bastos (1997):

$$
P I C=\frac{\text { diâmetrodatestemunha }- \text { diâmetrodotratamento }}{\text { diâmetrodatestemunha }} \times 100
$$

Os dados foram submetidos à análise de variância e as médias comparadas pelo teste de Tukey a $5 \%$ de probabilidade com auxílio do software AgroEstat.

Os fermentados utilizados foram fracionados antes da correção de $\mathrm{pH}$ e autoclavagem e enviados para a Central de Análises Instituto de Biotecnologia -Universidade de Caxias do Sul para análise dos compostos fenólicos por Cromatografia Liquida de Alta Eficiência (HPLC). As análises foram realizadas em equipamento HPLC marca HP modelo 1100, coluna Lichrospher $\mathrm{RP}_{18}(5 \mu \mathrm{m})$ equipado com detector UV a $210 \mathrm{~nm}$ e sistema quaternário de bombas. A análise em fase reserva foi constituída de: solvente A- água Milli-Q com 1\% de ácido fosfórico e solvente B- Acetonitrila. O sistema de bombeamento da fase móvel foi gradiente, com $90 \%$ do solvente A de 0 a $5 \mathrm{~min}, 60 \%$ de A de 5 a $40 \mathrm{~min}$ e $90 \%$ de A de 45 a 50 min. O fluxo padrão foi mantido a $0,5 \mathrm{~mL} / \mathrm{min}$ de acordo com Morelli (2010). As amostras foram solubilizadas em água Milli-Q (5 g/L) e filtradas em membranas de Nylon de $0,45 \mu \mathrm{m}$ de diâmetro de poro. Os compostos fenólicos foram identificados de acordo com sua ordem de eluição e por comparação de seu tempo de retenção com aqueles de seus padrões puros. A quantificação foi realizada pelo método de padronização externa, através da correlação da área $\left(m A U^{*} s\right)$ do pico do composto à curva padrão avaliado (ácido gálico, epigalocatequina, catequina, epicatequina, epigalocatequina galato, rutina, ácido ferulico, narangina, hespiredina, mirecetina, resveratrol, quercetina, apigenina e canferol). A análise foi feita em duplicata, sendo o resultado expresso em $\mu \mathrm{g} / \mathrm{mL}$ de extrato. 


\section{Resultados e Discussão}

A análise estatística indica que a utilização de fermentados na concentração de $10 \%$ apresentou baixa atividade de inibição sobre o crescimento micelial do fungo fitopatogênico, o mesmo ocorreu também na concentração de $20 \%$, sendo apresentada baixa porcentagem de controle sobre o crescimento do fungo C. fructicola. Na concentração de $40 \%$ do fermentado de S. terebinthifolia foi verificado inibição total sobre o desenvolvimento de C. fructicola. Tabela 1.

Tabela 1. Porcentagem de inibição do crescimento micelial de C. fructicola aos 14 dias de inoculação, em diferentes concentrações de fermentados botânicos.

\begin{tabular}{lccc}
\hline Tratamentos & $10 \%$ & $20 \%$ & $40 \%$ \\
\hline Schinus terebinthifolia & $33,16 \mathrm{~b}$ & $27,84 \mathrm{bc}$ & $100,00 \mathrm{a}$ \\
Psisum sativum & $5,85 \mathrm{bc}$ & $22,34 \mathrm{bc}$ & $26,96 \mathrm{bc}$ \\
Tagetes minuta & $6,18 \mathrm{bc}$ & $0,00 \mathrm{c}$ & $11,31 \mathrm{bc}$ \\
Trifolium pratense & $12,67 \mathrm{bc}$ & $9,85 \mathrm{bc}$ & $26,37 \mathrm{bc}$ \\
Ilex paraguariensis & $3,88 \mathrm{bc}$ & $9,50 \mathrm{bc}$ & $30,88 \mathrm{bc}$ \\
Vernonanthura tweediana & $7,59 \mathrm{bc}$ & $24,25 \mathrm{bc}$ & $1,62 \mathrm{bc}$ \\
Prunus myrtifolia & $21,34 \mathrm{bc}$ & $13,15 \mathrm{bc}$ & $16,72 \mathrm{bc}$ \\
Amaranthus hybridus & $10,74 \mathrm{bc}$ & $19,85 \mathrm{bc}$ & $18,68 \mathrm{bc}$ \\
\hline Testemunha & $0,00 \mathrm{c}$ & $0,00 \mathrm{c}$ & $0,00 \mathrm{c}$ \\
\hline DMS 5\% & \multicolumn{4}{c}{32,8777} \\
\hline
\end{tabular}

Médias seguidas pela mesma letra não diferem estatisticamente entre si pelo Teste de Tukey ao nível de 5\%, de probabilidade. Fonte: Autores.

A espécie Schinus terebinthifolia (Anacardiaceae), na literatura é conhecida por possuir propriedades antimicrobianas, antiviral, anti-inflamatória dentre outras ações (Cavalher et al., 2008); El-Massry, 2009; Freires at al., 2011; Alves et al., 2013). De acordo com de Lima et al. (2006), a análise química do extrato da casca de S. terebinthifolia revelou a presença de fenóis, triterpenos e antraquinonas, e este extrato foi ativo contra Staphylococcus aureus.

Resultados semelhantes sobre o desenvolvimento de Colletothichum spp, também foram verificados por Rebello (2013), avaliando frações de extratos de folhas e de casca de caule de S. terebinthifolia. As mesmas apresentaram atividade antimicrobiana para os fungos C. gloesporioides e C. musae, sendo diretamente ligada a estes efeitos biológicos a presença de compostos secundários como alcalóides, taninos, flavonóides e saponinas encontrados nas folhas e caule, principalmente os compostos fenólicos como flavonóides e taninos.

Resultados quanto ao controle de fungos fitopatogênicos utilizando extratos de plantas que permaneceram fermentado por um período médio de 15 dias foram verificados por Triaca et al., (2018), onde demonstraram que fermentados botânicos de plantas bioativas apresentaram atividade antifúngica no controle de fungos fitopatogênicos. E, Telaxka et al (2018), verificou que o biofermentado de Solanum mauritianum, apresentou resultados promissores com efeito antimicrobiano direto sobre a $X$. axonopodis pv. Phaseoli. Junior et al (2020) também verificaram atividade fungitóxica sobre Colletotrichum gloeosporioides utilizando óleo essencial e subproduto de sementes de Schinus terebinthifolius.

De acordo com Barros (2015), fitoalexinas podem ser produzidas pela planta, a partir do uso de extratos botânicos que tem constituintes vegetais que podem atuar como agentes fungistáticos e/ou fungicida, dependendo das concentrações utilizadas, além de um mesmo extrato poder ter ação sobre uma grande gama de microrganismos sendo estas propriedades dependentes de vários fatores tais como parte da planta utilizada, idade, estágio vegetativo, pH do solo, estação do ano e diferentes tipos de estresse. 
Trabalhos que utilizam preparados vegetais na proteção de plantas contra doenças, com destaque para os extratos, mostram seu potencial no controle de fitopatógenos, por sua ação biofungicida, inibindo o crescimento micelial e a germinação de esporos, e pela capacidade de induzir o acúmulo de fitoalexinas são sugeridos (Santos et al., 2014).

Segundo Laufenberg et al (2003); Hussain et al (2016), plantas e os resíduos destas contêm quantidades significativas de açúcares, proteínas, lipídios, minerais e outros compostos complexos que podem dar suporte físico e nutricional para o crescimento microbiano. Portanto a eficiência de determinados fermentados botânicos pode ser explicada devido a presença de microrganismos que permanecem presentes ou se desenvolvem durante o período da fermentação, isto pode favorecer a modificação química e biológica melhorando a eficácia do bioproduto, mas isso necessita ser melhor explorado.

E, segundo Sadh et al (2018), a fermentação é o processo de conversão biológica mais comum de matérias-primas baseadas em extratos de plantas modificadas por microrganismos. Por meio desse processo, os microrganismos têm a capacidade de transformar ou produzir compostos de alto valor ou produtos úteis para diferentes segmentos biotecnológicos aumentando os benefícios ambientais.

Durante a fermentação, as macromoléculas presentes no substrato são quebradas em unidades menores devido à ação de enzimas hidrolíticas extracelulares microbianas, e além disso, uma variedade de vias de como oxidação, redução, descarboxilação, glicosilação, metilação, acetilação dentro outras podem ocorrer, alterando a estrutura do composto e produzindo novos metabólitos e compostos bioativos. Hussain et al 2016, Gupta 2013.

Acreditasse que bactérias com potencial de crescimento em processos de fermentação de extratos botânicos podem promover a proteção sobre manejo de plantas cultivadas. Segundo Trias et al (2008), Shrestha et al (2014) as bactérias, além da função de probióticos também atuam na agricultura promovendo a saúde das plantas por meio de seu potencial antimicrobiano contra vários fitopatógenos. Desta maneira, a fermentação de espécies de plantas com potencial antimicrobiano podem ser convertidos por microrganismos endógenos e resultar em compostos bioativos de ação fungistático ou fungicida úteis para manejo de culturas agrícolas.

A proteção de culturas agrícolas contra fungos fitopatogênicos, através de técnicas como uso biopesticidas, extratos de plantas, indução de resistência, são métodos promissores, que promovem uma redução significativa no uso de produtos químicos de síntese, apresentando soluções para promoção alternativa sustentável soluções como agricultura orgânica (Rosnerand \& Markowitz, 2013). Desta maneira, a aplicação de extratos botânicos para o controle de doenças pode ser menos dispendiosa, facilmente disponível, não poluente e ecologicamente correta.

Os compostos fenólicos avaliados em duplicata por Cromatografia Liquida de Alta Eficiência (HPLC), dos fermentados botânicos estão representados na Tabela 2 . 
Tabela 2. Valores médios de concentração de compostos fenólicos $(\mu \mathrm{g} / \mathrm{mL})$ em fermentados botânicos, anterior à correção de pH e autoclavagem.

\begin{tabular}{|c|c|c|c|c|c|c|c|c|c|c|c|c|}
\hline Amostra & 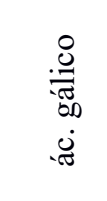 & $\frac{\widetilde{J}}{\stackrel{\Xi}{\Xi}}$ & 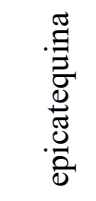 & 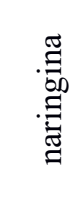 & 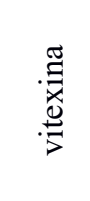 & 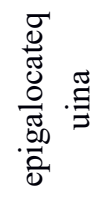 & 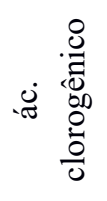 & $\stackrel{\Xi}{\Xi}$ & 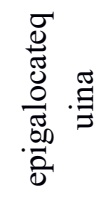 & 总 & 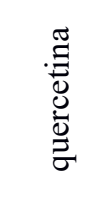 & 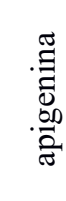 \\
\hline S. terebinthifolia & 210,8 & 7.1 & 1.4 & 5,0 & 32,1 & - & - & - & - & - & - & - \\
\hline Psisum sativum & 38.5 & - & 1.1 & - & - & 2.1 & - & - & 1.4 & 17.5 & - & - \\
\hline Tagetes minuta & 9.4 & - & 2.2 & 1.5 & - & - & - & - & 1.1 & - & - & - \\
\hline Trifolium pratense & 1.0 & 0.2 & - & - & - & - & - & 1.9 & 0.8 & - & - & - \\
\hline $\begin{array}{l}\text { Ilex } \\
\text { paraguarienses }\end{array}$ & - & - & 1.7 & - & 3.6 & 0.5 & 12.8 & - & - & - & 12.9 & - \\
\hline $\begin{array}{l}\text { Vernonanthura } \\
\text { tweediana }\end{array}$ & - & 0.5 & 0.9 & 4,2 & - & 0.5 & - & - & - & - & - & - \\
\hline Prunus myrtifolia & - & - & 20.8 & - & - & 26.8 & - & 42.7 & - & - & - & 2.0 \\
\hline $\begin{array}{l}\text { Amaranthus } \\
\text { hybridus }\end{array}$ & 0.7 & - & 0.8 & - & - & - & 12.7 & 1.7 & - & - & - & - \\
\hline
\end{tabular}

Fonte: Autores.

Foi constatado através da análise de HPLC que o fermentado botânico de S. terebinthifolia tem uma quantidade elevada do composto fenólico ácido gálico quando comparados aos demais fermentados.

$\mathrm{Na}$ literatura, o polifenol ácido gálico tem propriedades anti-inflamatórios (Saygin et al., 2016), efeitos antibacterianos (Lu et al., 2016), antifúngico natural Zhi-Jian et al (2017).

Produtos naturais, como extratos de plantas, têm propriedades antifúngicas para interromper o crescimento micelial e inibir a germinação de esporos de patógenos fúngicos devido à sua diversidade química. De acordo com os resultados obtidos, os compostos identificados em quantidades apreciáveis do fermentado de S. terebinthifolius incluem principalmente o composto fenólico ácido gálico. Os compostos fenólicos tem apresentado efeito efetivo no controle de fungos fitopatogênicas de forma eficaz. Huanran et al (2021).

Segundo Ceruks et al., (2007), destacam-se no fracionamento cromatográfico dos compostos fenólicos do extrato em etanol as folhas de aroeira-vermelha os compostos como galato de etila e de metila, a miricetrina, a quercitrina e a miricetina. Sendo que galato de metila são ésteres do ácido gálico em que estudos das relações de estrutura-atividade de uma série de nalquila ésteres do ácido gálico mostram maior atividade antifúngica que o próprio ácido gálico (Leal, 2004).

Rebello (2013) também cita a presença de flavonóides nos extratos de caule e folha de aroeira e indicaram ação bactericida pela ação antibiótica dos flavonóides que apresentam ação genotóxica e também pode estar relacionada à presença de taninos, que são compostos fenólicos que precipitam proteínas, propiciando um efeito antimicrobiano.

Deste modo a utilização do fermentado de $S$. terebinthifolia apresenta atividade antimicrobiana sobre diversos fungos e bactérias, dada pelas propriedades desta espécie que apresenta diferentes compostos fenólicos citados com ação sobre 
microrganismos, ou por ésteres do ácido gálico, flavonóides, taninos, e também pela indução de resistência e produção de fitoalexinas.

\section{Considerações Finais}

Os resultados obtidos neste trabalho comprovam que o fermentado botânico de $S$. terebinthifolia na concentração de $40 \%$ apresentou efeito antifúngico sobre Colletotrichum fructicola, inibindo $100 \%$ o crescimento micelial deste fungo fitopatogênico de importância para várias culturas agrícolas.

Maiores investigações devem ser realizadas sobre a atividade antimicrobiana dos diferentes compostos bioativas presentes nos fermentados botânicos a fim de validar esta alternativa na proteção de plantas cultivadas.

\section{Referências}

Alves, L. A., Freires, I. de A., Pereira, T. M., de Souza, L. E. de O., \& Castro, R. D. (2013). Effect of Schinus terebinthifolius on Candida albicans growth kinetics, cell wall formation and micromorphology. Acta Odontol Scand, 71(3-4), 965-971.

Andrade, E. R., \& Ducroquet, J. P. H. J. (1994). Antracnose em goiabeira serrana: caracterização, danos e perspectivas de controle. HortiSul, 3 (1), 19.

Araújo, A. C., Toledo, E. D., \& Soares, W. R. O. (2018). Produtos alternativos no controle de Colletotrichum spp. isolados de manga e banana. Cientific@Multidisciplinary Journal, 5 (3), 104 - 112. https://doi.org/10.20873/jbb.uft.cemaf.v7n3.barros

Bastos, C. N. (1997). Efeito do óleo de Piper aduncum sobre Crinipelis e outros fungos fitopatogênicos. Fitopatologia Brasileira, 22 (3), $441-443$.

Barros, L. S. (2015). Controle de fitopatógenos com extratos vegetais. Tese de Doutorado, Universidade Federal do Mato Grosso, Cuiabá, Brasil.

Bertrand, B. (2008). Plantas para curar plantas. (2a ed.), La fertilidad de la tierra. 107.

Cabral, L. da C., Pinto, V. F., Patriarca, A. (2013). Application of plant derived compounds to control fungal spoilage and mycotoxin production in foods. International Journal of Food Microbiology, 166 (1), 1-14.

Camatti-Sartori, V., Magrini, F. E., Crippa, L. B., Venturin, L., Silva-Ribeiro, R. T., Marchett, C. (2011). Avaliação in vitro de extratos vegetais para o controle de fungos patogênicos de flores,. Rev. Bras. de Agroecologia, 6 (2), 117-122.

Candido Silva, E. K., Melo, L. G. L. (2013). Manejo de doenças de plantas: Um enfoque agroecológico. Revista EDUCAmazônia - Educação Sociedade e Meio Ambiente. 10 (1), 143-157.

Cavalher-Machado S. C., Rosas E. C., Brito F. A., Heringe A. P., Oliveira R. R., Kaplan M. A. C., Figueiredo M. R., Henriques M. D. (2008). The antiallergic activity of the acetate fraction of Schinus terebinthifolius leaves in IgE induced mice paw edema and pleurisy. Int Immunopharmacol, 8, $1552-1560$.

Ceruks, M., Romoff, P., Fávero, O. A., Lago, J. H. G. (2007). Constituintes fenólicos polares de Schinus terebinthifolius Raddi (Anacardiaceae). Quim. Nova, $30(3), 597-599$.

Cruz, S. M. C. (2011). Ação indutora de produtos abióticos na resistência de tomateiro e efeito sobre o crescimento micelial de Fusarium oxysporum f. sp. Lycopersici. Idesia, 29 (2).

Dean, R., Kan, J. A. L. V., Pretorius, Z. A., Hammond-Kosack, K. E., Di Pietro, A., Spanu, P. D., Rudd, J. J., Dickman, M., Kahmann, R., Ellis, J., Foster, G. D. (2012). The Top 10 fungal pathogens in molecular plant pathology. Molecular Plant Pathology, 13 (4), 414-430. 10.1111/j.1364-3703.2011.00783.

Domingues, S. C. O., Matos, D. L., Carvalho, M. A. C., Rabelo, H. O., Yamashita, O. Y., Karsburg, I. V. (2020). Atividade antifúngica de extratos vegetais em Rhizoctonia sp. isolado de orquídea. Research, Society and Development, 9(8), http://dx.doi.org/10.33448/rsd-v9i8.5423

Lima, M. R., de Souza Luna, J., dos Santos, A. F., de Andrade, M. C., Sant Ana, A. E., Genet, J. P., Marquez, B., Neuville, L., \& Moreau, N. (2006). Antibacterial activity of some Brazilian medicinal plants. J Ethnopharmacol. 105, 137-147.

El-Massry, K. F., El-Ghorab, A. H., Shaaban, H. A. \& Shibamoto, T. (2009). Chemical compositions and antioxidant/antimicrobial activities of various samples prepared from Schinus terebinthifolius leaves cultivated in Egypt. J. Agric. Food Chem. 57, 5265-5270. https :// doi.org/10.1021/jf900 638c

Freires, I. A., Alves, L. A., Jovito, V. C., \& Castro, R. D. (2011). Atividade antifúngica de Schinus terebinthifolius (Aroeira) sobre cepas do gênero Candida. Rev Odontol Bras Central, 20(52), 41-45.

Gan, P., Nakata, N., Suzuki, T., \& Shirasu, K. (2016). Markers to differentiate species of anthracnose fungi identify Colletotrichum fructicola as the predominant virulent species in strawberry plants in Chiba Prefecture of Japan. Journal of General Plant Pathology, 83 (1), 1-9. 10.1007/s10327-016-0689-0

Gupta, A., Kagliwal, L. D., \& Singhal, R. S. (2013). Biotransformation of Polyphenols for Improved Bioavailability and Processing Stability. In Advances in Food and Nutrition Research, Taylor, S., Ed., Academic Press Inc. 69, 183-217. 
Huanran, W., Yazhu W., Zheng J, Fan Y., Jiajun H, \& Min-Tian G. (2021). Utilization of strawbased phenolic acids as a biofugicide for a green agricultural production. Journal of Bioscience and Bioengineering. 131 (1), 53-60. https://doi.org/10.1016/j.jbiosc.2020.09.007

Hussain, A., Bose, S.,Wang, J. H., Yadav, M. K., Mahajan, G. B., \& Kim, H. (2016). Fermentation, a feasible strategy for enhancing bioactivity of herbal medicines. Food Res. Int. 81, 1-16.

Johnny, L., Yusuf, U. K., \& Nulit, R. (2011). Antifungal activity of selected plant leaves crude extracts against a pepper anthracnose fungus, Colletotrichum capsici (Sydow) butler and bisby (Ascomycota: Phyllachorales). African Journal of Biotechnology, 10, 4157-4165.

Júnior, L. F. G. de O., A. P, Fontes, P. T. N, Oliveira, L. F. M., Santos, M. C., Gagliardi, P. R., \& Carnelossi, M. A. G. (2020). Chemical profile and potential antifungal of essential oil Schinus terebinthifolius and its by-products. Research, Society and Development, 9(11) http://dx.doi.org/10.334448/rsd-v9i11.106231

Leal, P. C. (2004). Síntese e avaliação da atividade antifúngica de compostos derivados do ácido gálico. 2004. 83 f. Dissertação (Mestrado em Química) Universidade Federal de Santa Catarina, Florianópolis, Santa Catarina.

Lopes, M. E. (2013). Caracterização morfológica de isolados de Colletotrichum sp., agente causal da antracnose em goiabeira-serrana (Acca sellowiana) (O. Berg.) Burret. Dissertação (Mestrado Recursos Genéticos Vegetais) Universidade Federal de Santa Catarina, Florianópolis, Santa Catarina.

Lu, J., Wang, Z. N., Ren, M. R., et al. (2016). Antibacterial effect of gallic acid against Aeromonas hydrophila and Aeromonas sobria through damaging membrane integrity. Curr Pharm Biotechnol, 17, 1153-1158.

Laufenberg, G., Kunz, B., \& Nystroem, M. (2003). Transformation of vegetable waste into value added products: (A) the upgrading concept, (B) practical implementations. Bioresour. Technol, 87, 167-198.

Melo, L. G. L. (2016). Indutores de resistência abióticos no controle da fusariose do abacaxi. Pesquisa Agropecuária Brasileira, 51 (10), $1703-1709$.

Morelli, L. L. L., (2010), Avaliação de compostos fenólicos majoritários em geleia de uva produzida com a variedade IAC-138-22 (máximo). Dissertação de Mestrado. Universidade Estadual de Campinas. Campinas, SP.

Naruzawa, E. S., \& Papa, M. F. S. (2011). Antifungal activity of extracts from brazilian Cerrado plants on Colletotrichum gloeosporioides and Corynespora cassiicola. Revista Brasileira de Plantas Medicinais, 13 (4), 408-412, 10.1590/S1516-05722011000400006

Nobre, J. O. S., \& Marques, M. L da S. (2021). Métodos alternativos para o controle in vitro de Colletotrichum gloeosporioides agente causal da antracnose em pimenta dedo-de-moça. Research, Society and Development, 10 (3). http://dx.doi.org/10.33448/rsdv10i3.13573

Parreira, D. F., Zambolim, L., Neves, W. S., Costa, R. V., Cota, L. V., \& Silva, D. D. (2014). A antracnose do milho. Revista Trópica-Ciências Agrárias e Biológicas, 8 (1), 11-27. 10.0000/rtcab.v8i1.1430

Peng, L. J., Sun, T., Yang, Y. L., Cai, L., Hyde, K. D., Bahkali, H., \& Liu, Z. Y. (2013). Colletotrichum species on grape in Guizhou and Yunnan provinces, China. Mycoscience, 54, 29-41. 10.1016/j.myc.2012.07.006

Pietrobelli, S. R. (2019). Eficiência de preparados vegetais no controle de doenças fúngicas e na indução de mecanismos de defesa em tomateiro. Dissertação (Mestrado em Agroecologia e Desenvolvimento Rural Sustentável) Universidade Federal da Fronteira Sul, Laranjeiras do Sul, PR.

Perina, F. J. (2014). Óleos essenciais e frações majoritárias ativas no controle da mancha marrom de alternaria (Alternaria alternata) em tangerina ponkan. 2014. 112f. Tese (Doutorado em Agronomia). Universidade Federal de Lavras, Lavras, MG.

Rebello, L. C. (2013). Atividade antimicrobiana dos extratos de Schinus terebinthifolius Raddi. 2013. 48 f. Dissertação (Mestrado em Agricultura Tropical) Universidade Federal do Espírito Santo, São Mateus.

Reis, A., Boiteux, L. S., \& Henz, G. P. (2009). Antracnose em Hortaliças da Família Solanacea. Embrapa Hortaliças, 9p. (Embrapa Hortaliças. Circular Técnico, 79).

Ribeiro, J. G., Serra, I. M. R. S., \& Araújo, M. U. P. (2016). Uso de produtos naturais no controle de antracnose causada por Colletotrichum gloeosporioides em mamão. Summa Phytopathologica, 42 (2), 160-164. 10.1590/0100-5405/2023

Rosnerand, D., \& Markowitz, G., (2013). Persistent pollutants: a brief history of the discovery of the widespread toxicity of chlorinated hydrocarbons. Environ. Res. 120,126-133

Sadh, P. K., Duhan, S., \& Duhan, J. S. (2018). Agro-industrial wastes and their utilization using solid state fermentation: A review. Bioresour. Bioprocess. 5 (10).

Santos, C. S., et al. (2014). Efeito do extrato de plantas no controle de fungos do tomateiro. Fragmentos de Cultura, 24 (1), 139-151.

Sartori. V. C., \& Venturin. L. (2016). Tecnologias alternativas para o fortalecimento da agricultura familiar na Serra Gaúcha. Educs.

Saygin, M, Asci, H, Ozmen, O, Cankara, F. N, Dincoglu, D, Ilhan, I. (2016). Impact of 2.45 GHz Microwave Radiation on the Testicular Inflammatory Pathway Biomarkers inYoung Rats: The Role of Gallic Acid. Environmental Toxicology. 10.1002.

Shrestha, A., Kim, B. S. \& Park, D. H. (2014). Biological control of bacterial spot disease and plant growth-promoting effects of lactic acid bacteria on pepper. Biocontrol Sci. Technol, 24, 763-779.

Silva, K. S., Rebouças, T. N. H., Lemos, O. L., Bomfim, M. P., Bomfim, A. A., Esquivel, G. L., Barreto, A. P. P., José, A. R. S., Dias, N. O., \& Tavares, G. M. (2006). Patogenicidade causada pelo fungo Colletotrichum gloeosporioides (Penz) em diferentes espécies frutíferas. Revista Brasileira de Fruticultura, 28 (1), 131-133 
Research, Society and Development, v. 10, n. 5, e48910515116, 2021

(CC BY 4.0) | ISSN 2525-3409 | DOI: http://dx.doi.org/10.33448/rsd-v10i5.15116

Tapia-Tussell, R., Lappe, P., Ulloa, M., Quijano-Ramayo, A., Cáceres-Farfán, M., Larqué-Saavedra, A., \& Perez-Brito, D. (2006). A rapid and simple method for DNA extraction from yeasts and fungi isolated from Agave fourcroydes. Molecular biotechnology, 33 (1), 67-70

Telaxka, F. J, Jaski, J. M., Scheffer, D. C., Gebauer, J. T., Moura, G. S., \& Franzener, G. (2018). Extrato aquoso e fermentado de fumo-bravo (Solanum mauritianum Scop) na proteção do feijoeiro (Phaseolus vulgaris L.) ao crestamento bacteriano comum. Revista Brasileira de Agropecuária Sustentável (RBAS), 8 (3), 81-90.

Toledo, M. V., Stangarlin J. R., \& Bonato, M. C. (2015). Controle da Pinta Preta e Efeito Sobre Variáveis de Crescimento em Tomateiro por Preparados Homeopáticos. Summa Phytopathologica, 41 (2), 126-132.

Triaca, T, Pansera, M. R, Andreolla, M. L, Venturin, L, \& Sartori, V. C. (2018). Avaliação in vivo do fermentado botânico de Ilex paraguariensis frente ao fungo Sclerotinia sclerotiorum no cultivo de alface crespa. Pesquisa Aplicada \& Agrotecnologia, Guarapuava-PR, 11 (1), 51-58. 10.5935/ PAeT.V11.N1.06

Trias, R., Bañeras, L., Montesinos, E. \& Badosa, E. (2008). Lactic acid bacteria from fresh fruit and vegetables as biocontrol agents of phytopathogenic bacteria and fungi. Int. Microbiol, 11, 231-236.

Venturoso, L. R., Bacchi, L. M. A., Gavassoni, W. L., Conus, L. A., Pontim, C. A., \& Bergamin, A. C. (2011a). Atividade antifúngica de extratos vegetais sobre o desenvolvimento de fitopatógenos. Summa Phytopathologica, 37 (1), 18-23. 10.1590/S0100-54052011000100003

Venturoso, L. R., Bacchi, L. M. A., Gavassoni, W. L., Conus, L. A., Pontim, B. C. A., \& Souza, F. R. (2011b). Inibição do crescimento in vitro de fitopatógenos sob diferentes concentrações de extratos de plantas medicinais. Arquivos do Instituto Biológico, 78 (1), 89-95.

Zhi-Jian, L., Meng, L., Gulina, D., Qin, D., Yu, M., Heng-Ge, L., \& Silafu, A. (2017). Antifungal Activity of Gallic Acid In Vitro and In Vivo. Phytother Res. Jul, 31(7), 1039-1045. 10.1002/ptr.5823. 